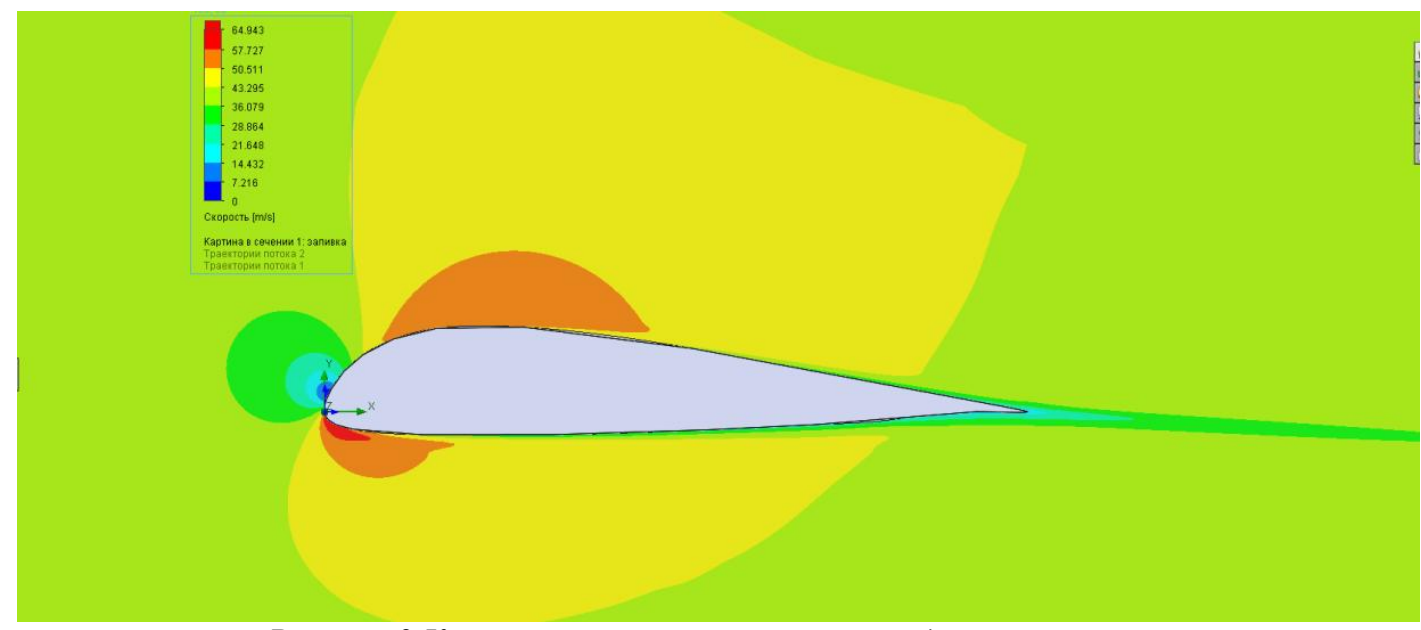

Рисунок 2 Картина изменения скорости воздушного потока

Профиль Р-III $(15,5)$ продувался в лаборатории ЦАГИ, в аэродинамической трубе Т-1, дата продувки 1932г. Сравниваем справочные коэффициенты реального эксперимента при $\alpha=-4^{\circ}$ с данными, полученными путем моделирования. Данные заносим в таблицу.

\begin{tabular}{|c|c|c|c|}
\hline $\begin{array}{c}\text { Аэродинамические } \\
\text { коэффициенты }\end{array}$ & Реальный опыт & Математический опыт & Погрлица 3 \\
\hline $\begin{array}{c}\text { Коэффициент лобового } \\
\text { сопротивления }\end{array}$ & 0.0142 & 0.017 & 19 \\
\hline $\begin{array}{c}\text { Коэффициент подъемной } \\
\text { силы }\end{array}$ & 0.04 & 0.042 & 0.05 \\
\hline
\end{tabular}

Результатом эксперимента стало получение коэффициентов подъемной силы и лобового сопротивления профиля Р-III $(15,5 \%)$ при угле атаки $\alpha=-4^{\circ}$ таблица 3 . Вывод на экран проекций динамических сил, действующих на крыло представлен в таблице 2. Также в процессе было получено распределение скорости воздушного потока, которое характеризует обтекание крыла рис.2.

$$
* * *
$$

1. А.С.Кравец Характеристики авиационных профилей. Государственное издательство оборонной промышленности. Москва, $1939-213 \mathrm{c}$.

2. SolidWorks. Компьютерное моделирование в инженерной практике. Алямовский А. А. и др., СПб.: БХВ-Петербург, 2005. - 800c.

\title{
Жуковский П.А. \\ RFID-системы: опыт внедрения и использования в библиотечной сфере
} филиал ФГБОУ ВО «НИУ «МЭИ»в г. Смоленске (Россия, Смоленск)

doi:10.18411/spc-12-04-2018-07

idsp: 000001:spc-12-04-2018-07

С появлением на рынке различных систем, способных идентифицировать объект на расстоянии, можно наблюдать рост использования таких технологий в различных сферах жизни, как пример: в библиотеках. RFID-системы (Radio Frequency IDentification) можно использовать для организации обслуживания посетителей библиотек, контроля перемещения книжных и других материалов хранения. RFIDтехнологии используют в некоторых больших российских библиотеках. В данной статье показан опыт внедрения систем радиочастотной идентификации на примере Ярославской областной универсальной научной библиотеки им. Н.А Некрасова. 
Технология RFID сильно выделяется на фоне штрихкода и имеет несколько серьезных преимуществ. Радиочастотное идентифицирование способно как заменить штрихкодирование, так и имеет задатки в использовании параллельно с ним. Первые разговоры о внедрении RFID-технологий пришлись на начало 2000-х годов, конференция LIBCOM была одной из первых. Очевидные преимущества RFID настолько сильно перекрывали свои недостатки, что моментально привлекали к себе внимание.

Основы работы любой RFID-системы: в блоке памяти транспондера записаны данные и присвоенный ей уникальный, личный номер. Тег при попадании в зону регистрирования считывателем сообщает ему информацию и личный номер, которые обрабатываются ридером. Пассивные метки не имеют источников энергии и потребляют энергию поля, вырабатываемую RFID-считывателем, для передачи информации. Накопив достаточную энергию для работы, транспондер способен передавать данные. Дистанция передачи пассивных транспондеров варьируется от 5 сантиметров до 8 метров, и зависит от типа и строения RFID-ридера.

Любая RFID-система должна иметь 3 составляющие:

RFID-транспондер - (также RFID-тег или RFID-метка) миниатюрное устройство, состоящее из микрочипа и антенны. Основная задача устройства посредством антенны транспортировать и принимать информацию, хранимую на чипе.

В библиотеку внедрена новая партия читательских билетов, каждый из которых представляет собой пластиковую карту с технологией RFID. Карта позволяет автоматизировать идентификацию пользователей. Приобретение читательских карт с введенными данными библиотеки не позволяет сделать билет персонифицированным. Следовательно, данные о клиентах находятся в базе данных библиотеки. Количество билетов на закупку определяется числом зарегистрированных клиентов библиотеки или библиотечного фонда.

Идентификационные метки (теги) - маленькие наклейки для книг или дисков. Каждый тег имеет свой уникальный код, по которому система библиотеки способно отличать один материал от другого. Каждая метка оборудована встроенной управляемой защитой от кражи. Любую метку можно перезаписать, таким образом разрешить или запретить вынос данного библиотечного материала.

RFID-ридер - (считыватель меток) прибор, задача которого считывать и записывать данные с RFID-меток. Считыватели связаны с системами учета данных с транспондеров (меток), а также имеют возможность работать автономно.

Универсальная станция-считыватель которая организует книговыдачу и программирование тегов (меток) позволяет автоматически активировать/деактивировать метки, следить за статусом единицы хранения. Станция состоит из считывающего устройства, которое передает данные в АБИС, панели считывания меток, компьютера и источника питания.

Ворота, защищающие библиотеку от несанкционированных выносов, реагируют на RFID-теги материалов, которые не прошли деактивацию на станции выдачи книг или запрещённые на вынос из библиотеки или определенного зала. Воротами управляются по локальной вычислительной сети с помощью специального ПО с полной интеграцией с АБИС. Ворота представляют собой: пара антенн, контроллер, звуковая или световая сигнализация, или их комбинация. Дистанция между антеннами не менее 0.914 м (соблюдая требования для беспрепятственного прохода инвалидных колясок).

Система Учета - специальное программное обеспечение, способное записывать и обрабатывать данные, полученную RFID-меток, связывая элементы друг с другом в общую систему.

RFID - инновационная технология, которая способна реорганизовать работу как одной библиотеки, так и всю систему обслуживания библиотечной сферы. 
Происходят изменения структуры библиотеки, технологических процессов, а также большую долю несут изменения должностных обязанностей работников библиотек и библиотечных фондов. Результатом внедрения в обиход новых методов идентификации можно выделить некоторые пункты:

- Удалось уменьшить влияние человеческого фактора, сократить количество ошибок идентификации;

- Новый уровень охраны книжного фонда от несанкционированных выносов книжных материалов;

- Увеличена скорость обслуживания посетителей за счет внедрения станций самообслуживания посетителей

$$
\text { *** }
$$

1. Власов M. M. RFID: 1 технология - 1000 решений. - Москва: Альпина Паблишер, 2014.

Калюжин В.А., Максименко Л.А., Черноножкина С.А. Состояние и пути дальнейшего развития дисциплины «Информационные системы в землеустройстве и кадастре»

Сибирский государственный университет геосистем и технологий (Россия,Новосибирск)

doi:10.18411/spc-12-04-2018-08

idsp: 000001:spc-12-04-2018-08

\section{Аннотация}

В период бурного развития цифровых и информационных технологий объем вовлечения в оборот объектов недвижимости, и уровень инвестиционной привлекательности территорий будет, зависит от способности специалистов использовать современные технологии сбора, обработки и учета информации об объектах недвижимости. И это обуславливает повышение требований к качеству образовательного процесса при подготовке бакалавров по направлению «Землеустройства и кадастры».

Качество образовательного процесса определяют ряд факторов, одними из них являются: содержание образовательных программ, в том числе содержание рабочих программ дисциплин, организация и контроль образовательного процесса и т.д.

В образовательной программе подготовки бакалавров по данному направлению эти способности (компетенции) преимущественно формируются в дисциплинах профессионального цикла, в том числе в курсе «Информационные системы в землеустройстве и кадастре» (ИСвЗиК).

Следовательно, современные требованиям к качеству образования обуславливают модернизацию рабочей программы дисциплины ИСвЗиК. Для решения этой задачи применили системный анализ, монографический, аналитический и экспертный методы.

В результате разработано новое содержание рабочей программы ИСвЗиК, отличительной чертой которой является комплексный подход к формированию у обучающихся способности объединять и интегрировать современные специализированные прикладные программы, геоинформационные и CAD системы, и геопорталы при решении научно-технических задач в землеустройстве и кадастре.

Предлагаемая организация самостоятельной работы, балльно - рейтинговая система и индивидуальный подход формирования практических навыков позволить повысить как качество освоения необходимых компетенций, так и конкурентоспособность бакалавра на рынке труда.

Ключевые слова: федеральный образовательный стандарт, компетенции, ГИС и $\mathrm{CAD}$ системы, специализированные прикладные программы, землеустройство и кадастр, требования, подход, рабочая программа дисциплины, балльно - рейтинговая система, геоматика. 